\author{
Astrid Dwi Cahyaningtyas ${ }^{1}$ dan Setiamurti Rahardjo ${ }^{2}$ \\ Program Studi Desain Interior \\ Universitas Telkom \\ 'astridutha@yahoo.co.id \\ icusrahardjo@tcis.telkomuniversity.ac.id
}

\title{
PENGGUNAAN KONSEP SPACE SAVING UNTUK APARTEMEN TIPE STUDIO DI KOTA BANDUNG
}

\begin{abstract}
Abstrak: Apartemen merupakan sebuah tempat tinggal layaknya rumah pada umumnya, hanya saja tiaptiap hunian disusun secara vertikal dan terdiri dari beberapa tipe untuk menunjang kebutuhan penghuninya. Apartemen tidak muncul dengan sendirinya tanpa adanya fenomena yang terjadi pada lingkungan tersebut, seperti halnya Apartemen The Suites at Metro, Apartemen Gateway Pasteur, ataupun Apartemen Sudirman Suite yang ketiganya berada di Kota Bandung. Apabila dilihat dari luas ruang tiap unitnya, tipe studio merupakan tipe apartemen yang memiliki beberapa kekurangan, terkait dengan pemanfaatan ruangnya karena tipe studio merupakan sebuah hunian yang di dalamnya hanya memiliki sebuah ruang duduk untuk mendukung berbagai macam kegiatan penghuni yang juga dapat dialihfungsikan sebagai ruang tidur, ruang makan, ruang keluarga, ruang tamu serta dapur (selain kamar mandi). Dalam hal penggunaan dimensi dan peletakan furnitur, pengaplikasian konsep 'space saving' yang berkembang dari negara bagian barat diharapkan dapat memberikan bentuk yang baru pada hunian apartemen tipe studio di Bandung. Konsep space saving sendiri berhubungan langsung dengan penggunaan dimensi furnitur serta penggabungan beberapa kebutuhan fungsi benda pada sebuah furnitur, yang biasa dikenal dengan furnitur convertible. Penelitian ini dilakukan dengan metode kuantitatif dimana data didapat dari kegiatan observasi objek studi, mengukur langsung ukuran dimensi fisik apartemen, dan menganalisis data dengan melakukan simulasi layout rangkaian convertible pada tiap sampel layout yang ada. Penelitian ini dilakukan untuk menunjukkan kesesuaian konsep space saving apabila diaplikasikan pada layout apartemen studio yang ada di Indonesia, khususnya di daerah Bandung. Pada akhirnya, penelitian ini dapat menghasilkan sebuah 'patokan' baru yang dapat digunakan pada setiap interior apartemen tipe studio.
\end{abstract}

Kata kunci: apartemen, furnitur convertible, space saving, studio

\begin{abstract}
Apartment is one of settlements, each of which is arranged vertically and consists of several types of residential units to supportthe needs of the occupants. Apartment does not appear without any phenomenon that occurs in the environment, as happens at The Suite at Metro Apartment, Gateway Pasteur Apartment, and Sudirman Suite Apartment all of which are located in Bandung. Analyzing from the living space of each unit, studio apartment has some issues related to the use of space. Studio apartment is a type of apartment which consists of one multifunctional space for various activities such as bedroom, dining room, living room and kitchen; and a bathroom. In terms of furniture layout and dimensions the implementation of space saving concept developed in the western countries to studio
\end{abstract}


apartment in Bandung is ecpected to bring a new form to residential studio apartment. The space saving concept itself is directly related to the use of furniture dimension as well as merging several functional needs in a furniture, commonly known as 'convertible furniture'. This research is conducted using quantitative method and the data is obtained from observing the object of study, measuring directly the size of physical dimensions of studio apartment, and analyzing the data by simulating the convertible furniture on each of the existing layouts. This research indicates the sustainability of the space saving concept when applied to the layout of studio apartment in Indonesia, particularly in the area of Bandung. Eventually, the research is able to create a new standard that can be used in any of studio apartment.

Keyword: Apartment, Convertible Furniture, Space Saving, Studio

\section{Pendahuluan}

\subsection{Apartemen sebagai Kebutuhan Sosial}

Apartemen saat ini marak dijadikan sebagai tempat tinggal layaknya rumah. Hal ini terjadi karena fenomena tingginya kebutuhan masyarakat akan tempat tinggal yang tidak sebanding dengan ketersediaan lahan yang ada, khususnya untuk landed house. Bentuk yang vertikal ke atas membuat bangunan ini dapat menampung banyak penghuni untuk tinggal di dalamnya. Keberadaan apartemen merupakan hasil dari kebutuhan sosial dan berbagai macam jenis akomodasi, baik pada bidang ekonomi, sosial, politik, agama maupun budaya. Ukuran, wujud fisik secara visual, lokasi serta bentuknya tidak dengan mudah diatur berdasarkan faktor fisiknya, tetapi berdasarkan ide sosial (Anthony D. King, 1984). Sehingga dapat dikatakan apartemen merupakan solusi dari permasalahan yang ada pada sektor hunian. Keberadaan apartemen mulai merambah ke area-area pinggir kota. Hal ini terjadi untuk menyesuaikan kebiasaan hidup masyarakat yang lebih mengedepankan kepraktisan serta efisiensi dalam berkegiatan. Perbedaan antara apartemen dan rumah susun atau rusunami terletak pada pengembang yang mengelola properti dari apartemen atau rusunami. Apartemen dibangun oleh pengembang swasta dengan biaya kepemilikan yang mahal, sedangkan rumah susun atau rusunami dibangun berdasarkan program pemerintah daerah dengan biaya kepemilikan yang murah dibandingkan apartemen karena sebagian dananya disubsidi oleh pemerintah.

Dilihat dari luasan tiap ruang huniannya, apartemen tipe studio merupakan tipe apartemen yang memiliki kekurangan, terkait dengan pemanfaatan ruang dalam interiornya dibandingkan dengan ruang apartemen tipe keluarga ataupun tipe bisnis. Pada apartemen tipe studio, satu ruangan besar kecuali kamar mandi, harus dapat menampung berbagai jenis kegiatan penghuni dan dapat beralih fungsi menjadi ruangan lain, meliputi ruang tidur, ruang makan, ruang TV/ keluarga/ ruang tamu, serta dapur. Merujuk pernyataan 'Bagian Pemasaran' The Suites 
at Metro, tidak adanya pembagian ruang secara visual membuat apartemen tipe studio cocok diperuntukkan bagi mahasiswa atau eksekutif muda yang masih belum berkeluarga. Selain menjadi hunian, apartemen dapat digunakan sebagai tempat kerja. Oleh karena luas ruangnya yang terbatas, dibutuhkan sebuah konsep ruang yang dapat memfasilitasi semua kegiatan pengguna di dalamnya. Salah satunya adalah dengan konsep space saving.

\section{Penggunaan Furnitur Convertible pada Apartemen Studio}

Kenyamanan ruang gerak manusia didalamnya bergantung pada tata letak furnitur sebagai penunjang berkegiatan penghuni serta dimensi dari furnitur itu sendiri. Peletakan dan dimensi furnitur akan memengaruhi pola sirkulasi yang terbentuk di dalam hunian. Luasan terbatas yang disediakan pada sebuah hunian apartemen tipe studio membuat beberapa furnitur di dalamnya perlu dipadatkan ke dalam sebuah furnitur dengan fungsi sejenis. Penggunaan fungsi yang lebih pada satu ruang dapat meminimalisir penggunaan furnitur secara berlebih dan dapat menyisakan ruang lebih banyak pula untuk sirkulasi. Penggunaan furnitur dengan fungsi yang banyak disebut juga dengan furnitur convertible. Furnitur convertible adalah furnitur yang dapat berubah bentuk, fungsi dan karakter sesuai dengan kebutuhan pengguna pada saat itu. Selain memfokuskan fungsi pada sebuah bentuk furnitur yang sama, dimensi furnitur seperti panjang, lebar, dan tinggi furnitur juga perlu diperhatikan agar dapat menghasilkan bentukan ruang yang baik.

Furnitur convertible digunakan pada apartemen tipe studio agar ruangan menjadi lebih luas dalam hal dimensi yang terbentuk di dalam ruangan apabila furnitur-furnitur yang ada dalam keadaan tidak terpakai. Furnitur convertible sendiri telah digunakan oleh Raanan Stern (2014), seorang desainer yang menciptakan sebuah konsep space saving yang diaplikasikan pada ruangan seluas $15 \mathrm{~m}^{2}$ dengan menggunakan furnitur convertible sebagai pendukung kegiatan penghuni.

Penelitian ini dimaksudkan untuk mengetahui bisa atau tidaknya sebuah konsep hunian berupa space saving yang diaplikasikan pada beberapa layout apartemen studio yang ada di Bandung dengan menggunakan furnitur modular dan convertible agar sesuai dengan kebutuhan penghuni. Sehingga, pengguna dapat berkegiatan di dalamnya dengan bebas tanpa terhalang oleh keterbatasan luas ruang. Pada akhirnya, penelitian ini dapat menghasilkan sebuah kriteria konsep space saving dengan menggunakan furnitur convertible dan dapat diaplikasikan pada tiap bentuk serta ukuran layout apartemen studio yang ada di Bandung. 


\section{Kajian Literatur}

\subsection{Konsep Space Saving pada Apartemen Studio}

Konsep space saving sendiri sudah ada sejak 1915, namun penggunaannya terhadap ruang interior belum begitu populer, khususnya di Kota Bandung. Konsep space saving digunakan untuk menciptakan sebuah interior apartemen studio agar terlihat lebih lapang/ luas dengan luas area yang terbatas. Salah satu contoh penggunaan konsep space saving dapat terlihat pada karya yang didesain oleh Raanan Stern (2014). Raanan Stern menerapkan konsep space saving pada ruangan dengan ukuran $15 \mathrm{~m}^{2}$ yang terdiri dari dua meja kerja, 36 kabinet penyimpanan (modular), serta kasur lipat.

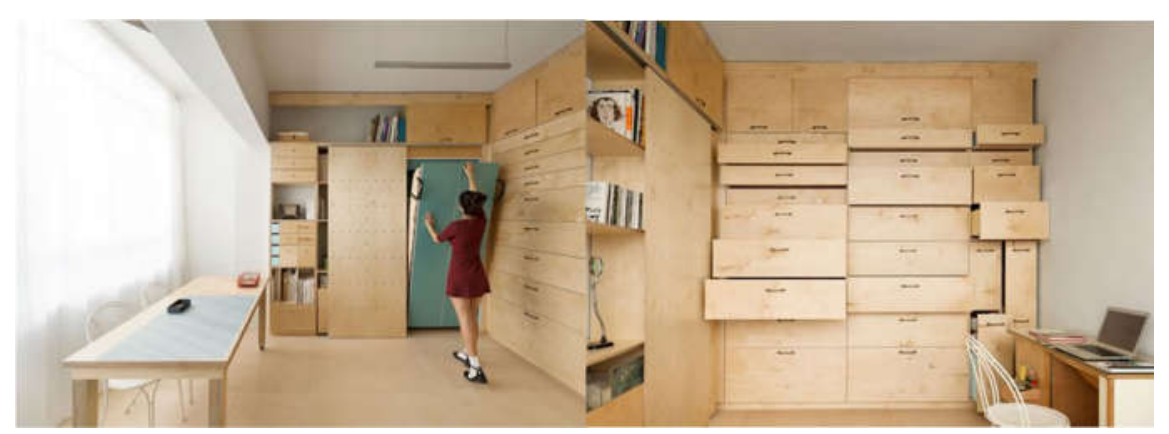

Gambar 1. Desain ruangan karya Raanan Stern (sumber: http://www.dezeen.com)

Tujuan dari space saving adalah membuat ruangan dengan luas yang terbatas dapat menampung semua kebutuhan serta kegiatan penghuni tanpa membutuhkan banyak komponen furnitur di dalamnya. Selain meminimalisasi kebutuhan furnitur pada apartemen tipe studio, pembagian dan penataan ruang dapat disiasati dengan menggunakan elemen dekoratif interior berupa karpet serta pembatas ruang semu, seperti tirai atau rak buku (Imelda Akmal, 2007:4790). Sehingga diharapkan nantinya akan menghasilkan pemanfaatan ruang yang lebih bijak dengan luasan terbatas terhadap furnitur.

\subsection{Karakteristik Apartemen Tipe Studio}

Apartemen tipe studio tidak selalu memiliki luasan serta bentuk layout yang sama. Mengacu pada standar apartemen pada Gambar 2 yang terdapat pada Data Arsitek Jilid II (Ernst 
Neufert, 1994:92), bentuk layout yang terdapat pada apartemen studio di Indonesia, khususnya di Bandung tidaklah sama. Namun demikian, terdapat keserupaan pada bentuk layout dan luasan berbagai apartemen studio di Bandung pada umumnya, meski secara spesifik akan akan ditemukan perbedaan.

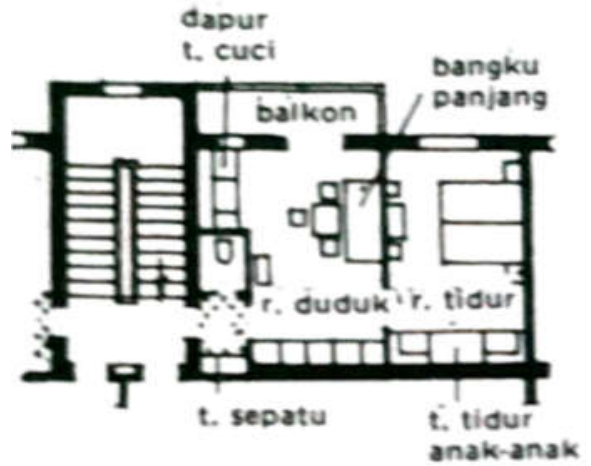

Gambar 2. Layout Standar Apartemen Studio (sumber: Data Arsitek Jilid 2)

Apartemen tipe studio dikenal dengan luasannya yang terbatas, membuat desainer dan pengembang perlu jeli dalam menyiasati ruang apartemen. Sehingga dapat diciptakan bentukan ruang yang nyaman. Seperti halnya di Bandung, banyak apartemen yang mulai didirikan sebagai fasilitas penunjang hunian tinggal dengan berbagai macam bentuk dan dimensi pada masingmasing layout.

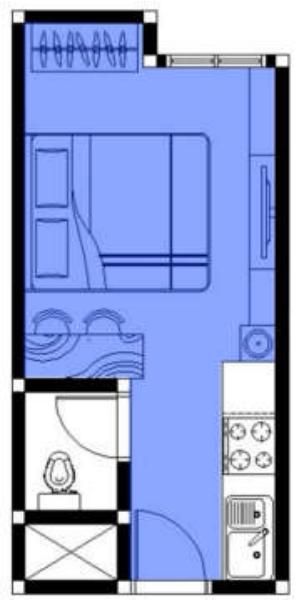

( A )

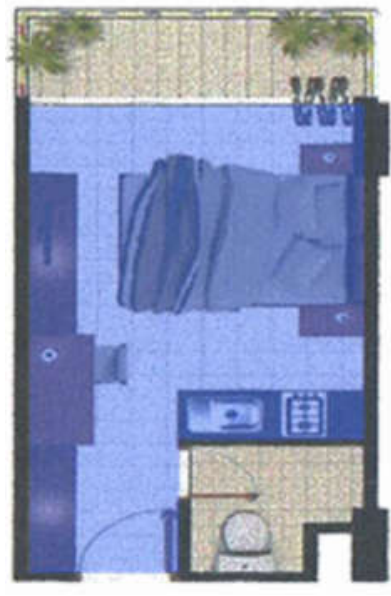

( B )

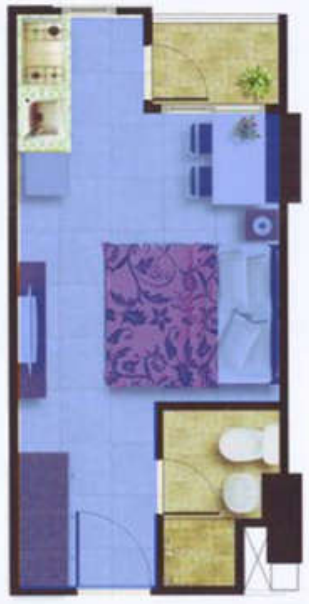

( C )

Gambar 3. Denah Apartemen The Suites at Metro (A), Gateaway Pasteur (B), dan Sudirman Suite (C) (sumber: Analisa Penulis) 
Pada ketiga layout di atas, terlihat perbedaan peletakan furnitur serta pembagian ruang dalamnya. Area arsir berwarna biru merupakan area yang menjadi fokus utama pada penelitian. Pada layout A, B, dan C, pembagian ruang yang diarsir terdiri atas area dapur kecil (pantry), area tempat tidur, area TV, dan area kabinet pakaian. Masing-masing luasan dari denah apartemen di atas pun berbeda-beda. Denah A memiliki luas $21 \mathrm{~m}^{2}$, denah B memiliki luas $23 \mathrm{~m}^{2}$, sedangkan denah C memiliki luas $19,5 \mathrm{~m}^{2}$. Sehingga secara general area yang terbagi dalam sebuah apartemen studio adalah dapur kecil (pantry), meja multifungsi (bisa digunakan sebagai meja makan atau meja kerja), tempat tidur, serta area TV.

\subsection{Standar Dimensi Furnitur pada Apartemen Tipe Studio}

Secara umum, apartemen tipe studio hanya memiliki dua ruang utama, yaitu kamar mandi dan area besar yang berfungsi menampung semua kegiatan penghuni di dalamnya. Standar dimensi tiap-tiap furnitur pada dasarnya berpedoman pada standar furnitur yang sudah ada pada buku Data Arsitek. Berdasarkan Gambar 3 di atas, kebutuhan ruang pada layout apartemen terbilang sama. Berdasarkan area yang diarsir (Gambar 3) ruang yang dibutuhkan pada sebuah apartemen, antara lain area tidur, area TV berupa credenza, area kabinet penyimpanan, serta area makan. Berikut standar dimensi yang digunakan pada tiap area:

Tabel 1. Standar Dimensi Furnitur

(sumber: Data Arsitek Jilid 1 dan 2)

\begin{tabular}{|l|l|c|}
\hline \multicolumn{1}{|c|}{ Area } & \multicolumn{1}{|c|}{ Furnitur yang dibutuhkan } & $\begin{array}{c}\text { Dimensi panjang x lebar } \\
\text { (cm) }\end{array}$ \\
\hline Tempat Tidur & A. Kasur & $200 \times 80$ \\
\hline Area TV & B. Credenza & $120 \times 45$ \\
Cabinet & C. Fasilitas Duduk (sejenis sofa) & $200 \times 75$ \\
Penyimpanan & D. Lemari Pakaian & $125 \times 60$ \\
\hline Area Makan / & F. Meja & $80 \times 50$ \\
Kerja & G. Kursi & $80 \times 60$ \\
\hline \multirow{2}{*}{ Dapur } & H. Kabinet (lemari bawah) & $45 \times 45$ \\
& I. Sink & $60 \times 60$ \\
& J. Kompor & $45 \times 45$ \\
& K. Kabinet (rak) & $55 \times 50$ \\
& L. Kulkas kecil & $60 \times 35$ \\
\hline
\end{tabular}


Data dimensi pada Tabel 1 dijadikan sebagai data acuan dasar dalam merancang furnitur convertible yang akan digunakan pada apartemen studio. Dimensi-dimensi furnitur utama yang dibutuhkan pada tiap area diringkas dalam sebuah furnitur convertible yang dirancang dengan beberapa opsi. Dilihat dari dimensi lebar yang tertera pada standar dimensi furnitur Data Arsitek, lebar dimensi ideal yang cocok diaplikasikan pada apartemen studio berkisar antara 45-60 cm.

\section{Metode Penelitian}

Penelitian menggunakan metode kuantitatif, di mana data didapatkan dari tahap survei, observasi (melihat keadaan fisik contoh apartemen tipe studio secara langsung), mengukur fisik dimensi apartemen serta pengumpulan data melalui studi literatur yang diperoleh dari beberapa sumber literatur. Data hasil mengukur fisik dimensi kemudian dibandingkan dengan studi literatur yang didapat serta dilakukan simulasi dengan cara mengimplementasikan furnitur pada tiap contoh layout yang ada.

Adapun dalam pengumpulan data, tahapan-tahapan yang dilakukan adalah sebagai berikut:

\section{A. Wawancara}

Pengumpulan data dilakukan melalui wawancara dengan 'Bagian Pemasaran' Apartemen The Suites at Metro. Tujuannya untuk mengetahui informasi tentang apartemen dan penghuni/ pengguna apartemen tipe studio.

B. Observasi

Pengumpulan data dilakukan dengan cara mengamati objek penelitian berupa ruangan apartemen tipe studio, mencatat langsung hal-hal yang berkaitan dengan penelitian, serta mengukur dimensi fisik apartemen. Berikut merupakan data yang didapat dari hasil observasi pada apartemen The Suites at Metro, Bandung:
a. Mengukur dimensi furnitur yang digunakan pada ruangan
b. Mengukur seberapa banyak ruang yang tersisa untuk sirkulasi manusia
c. Mengukur dimensi satu ruang kamar apartemen
d. Mencatat fasilitas yang tersedia pada satu ruangan
e. Mencatat pembagian ruang semu pada satu ruangan

\section{Dokumentasi}

Dokumen berupa foto atau gambar mengenai objek penelitian. Adanya dokumentasi, hasil observasi dan wawancara akan menjadi sah dan dapat dipercaya kebenarannya.

D. Studi Literatur 


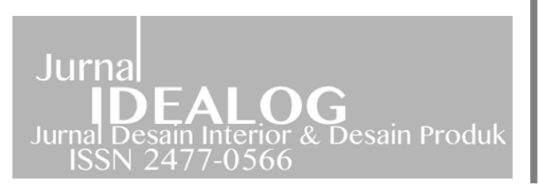

Pengumpulan data yang dilakukan dengan mempelajari buku-buku referensi, laporan/jurnal terpercaya, majalah, serta media lainnya yang masih berhubungan dengan objek penelitian. Berikut adalah buku yang dijadikan referensi pada penelitian ini, diantaranya:

a. Data Arsitek Edisi Kedua (1994) oleh Ernst Neufert

b. Dimensi Manusia \& Ruang Interior (1979) oleh Julius Panero dan Martin Zelnik

c. Housing (1975) oleh John Mascai

d. Time-Saver Standards for Building Types 2nd Edition (1983) oleh Joseph De Chiara dan John Callender

E. Analisis

Menganalisa data-data yang didapatkan dengan hasil berupa data numerik pada tabel dan mengimplementasikan data hasil analisis pada beberapa contoh layout sehingga memperoleh kesimpulan.

\section{Pembahasan}

Untuk dapat membandingkan contoh yang terjadi di 'lapangan' dengan standar furnitur yang sudah ada, dibutuhkan sebuah contoh layout apartemen sungguhan dan belum mengaplikasikan konsep space saving pada interiornya. Sehingga ruangan yang tersisa bagi penghuni untuk bergerak secara leluasa sangatlah sedikit. Sebagai studi kasus, penelitian ini membahas tentang apartemen tipe studio yang ada di Kota Bandung, di antaranya apartemen The Suites at Metro, J1. Soekarno Hatta No. 689, Bypass - Bandung; apartemen Gateway Pastur, J1. Gunung Batu 29-30, Bandung; dan apartemen Sudirman Suite di Jl. Jend. Sudirman, Dungus Cariang, Bandung. Apartemen-apartemen tersebut dipilih karena memiliki keragaman ukuran layout serta perbedaan peletakan beberapa ruang di dalamnya (Gambar 1) : 


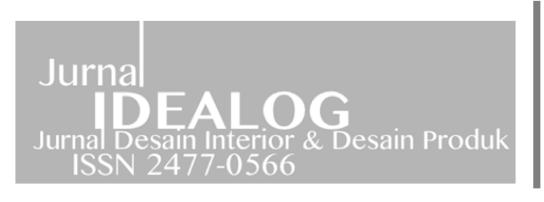

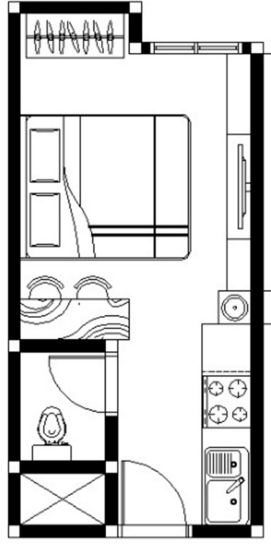

(A)

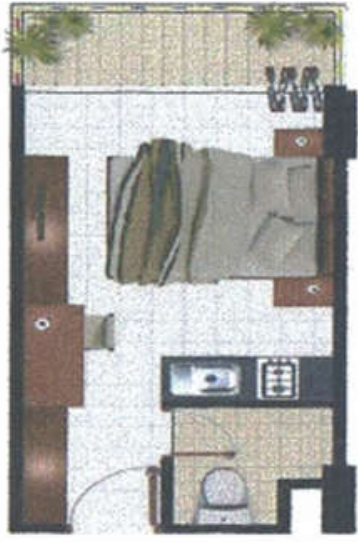

(B)

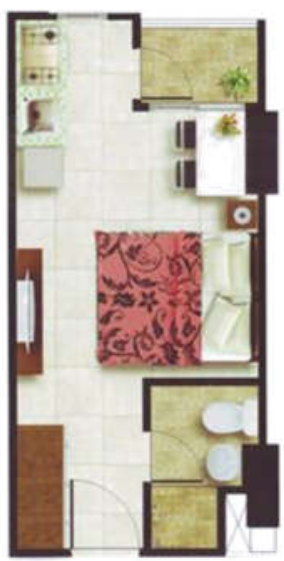

(C)

Gambar 4. Sample Layout Apartemen yang Digunakan: The Suite at Metro (A), Gateway Pasteur (B), dan Sudirman Suite (C)

(sumber: Data Pribadi)

Gambar 4 memperlihatkan suasana apartemen tipe studio pada ketiga contoh denah layout yang digunakan pada penelitian ini. Tiap apartemen tipe studio memiliki desain dan peletakan furnitur yang terlihat sama. Hal yang berbeda pada ruangan tersebut adalah pembagian area pada tiaptiap layout. Ketiga layout di atas, nantinya akan digunakan dalam penelitian untuk memperlihatkan pengaplikasian konsep space saving pada apartemen yang ada di Indonesia, khususnya di Kota Bandung.

Dengan sebuah ruang besar yang digunakan untuk menunjang kehidupan penghuni yang tinggal di dalamnya, membuat ruang apartemen tipe studio ini menjadi sebuah tempat yang dituntut untuk memiliki fungsi yang banyak. Konsep space saving dengan menggunakan furnitur convertible diimplementasikan kepada tiap denah guna melihat kesesuaian konsep space saving bila diterapkan pada tiap layout apartemen studio yang berbeda. 
Tabel 2. Luas dan Sirkulasi Layout Eksisting (sumber: Analisis Penulis)

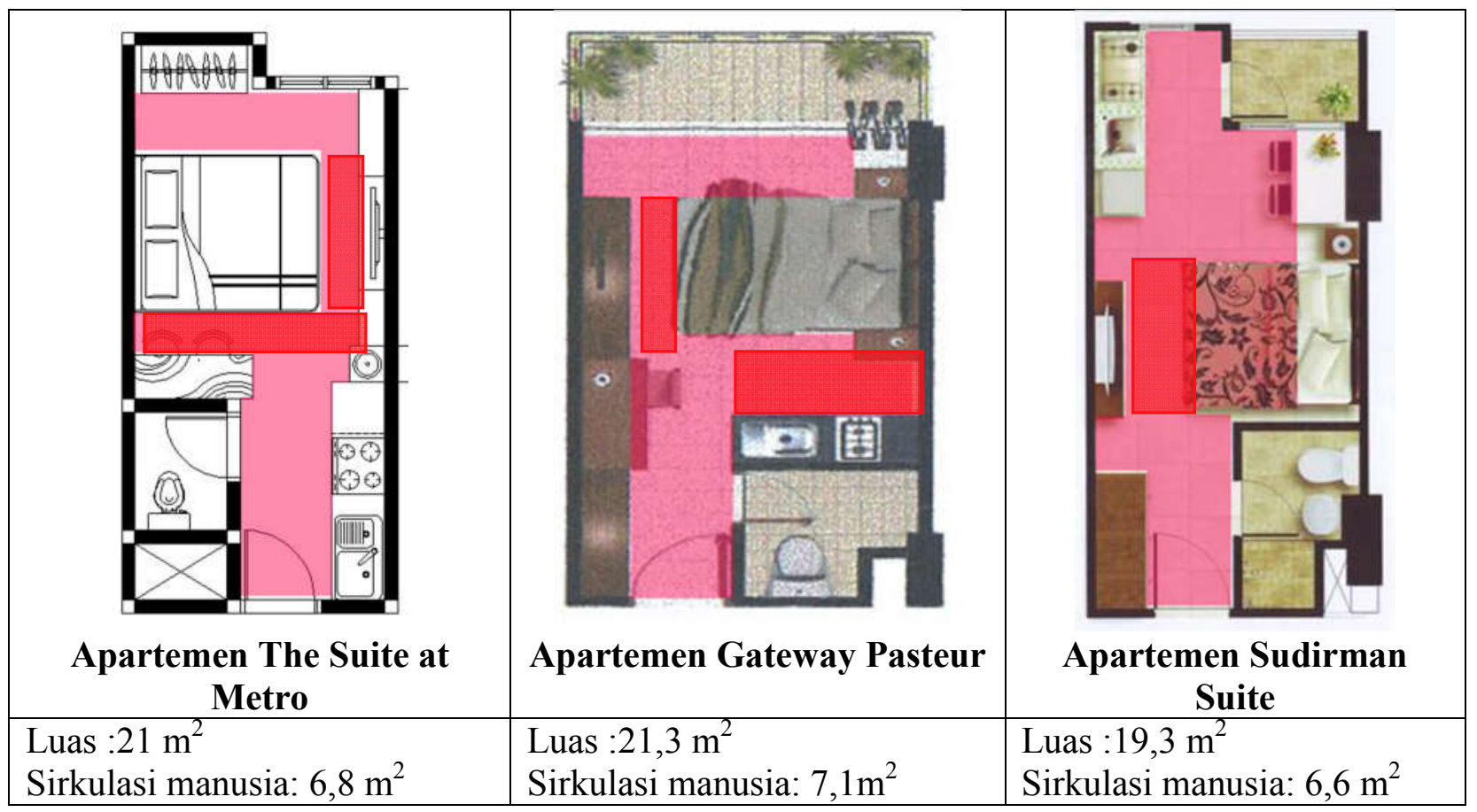

Tabel 2 menunjukkan area sirkulasi penghuni bila beraktivitas di dalam apartemen (arsir merah transparan) serta menunjukkan area sirkulasi yang bermasalah (arsir merah) karena penggunaan dimensi furnitur yang kurang sesuai dengan ukuran serta bentuk apartemen. Sesuai dengan pernyataan Imelda Akmal (2007), ada baiknya bahwa apartemen tipe ini menggunakan jenis furnitur yang lebih kecil ukurannya atau sama dengan ukuran standard pada umumnya, berbentuk modular, serta multifungsi. Sehingga dimensi tiap sudut apartemen dapat dimaksimalkan dengan baik.

Konsep space saving pada ruang apartemen didukung dengan penggunaan rangkaian furnitur yang convertible. Rangkaian furnitur convertible sendiri terbagi atas dua tipe rangkaian, yaitu tipe gabungan (rangkaian furnitur berbentuk L dan lurus) serta berbentuk U. Kedua jenis rangkaian furnitur convertible yang ada digunakan untuk memaksimalkan ruang apartemen dengan baik, terutama area yang bersebelahan langsung dengan dinding. Berikut implementasi konsep space saving melalui furnitur convertible pada ketiga sampel layout yang digunakan: 
Tabel 3. Implementasi Konsep Space Saving dalam Bentuk Furnitur Convertible (sumber: Analisis Penulis)

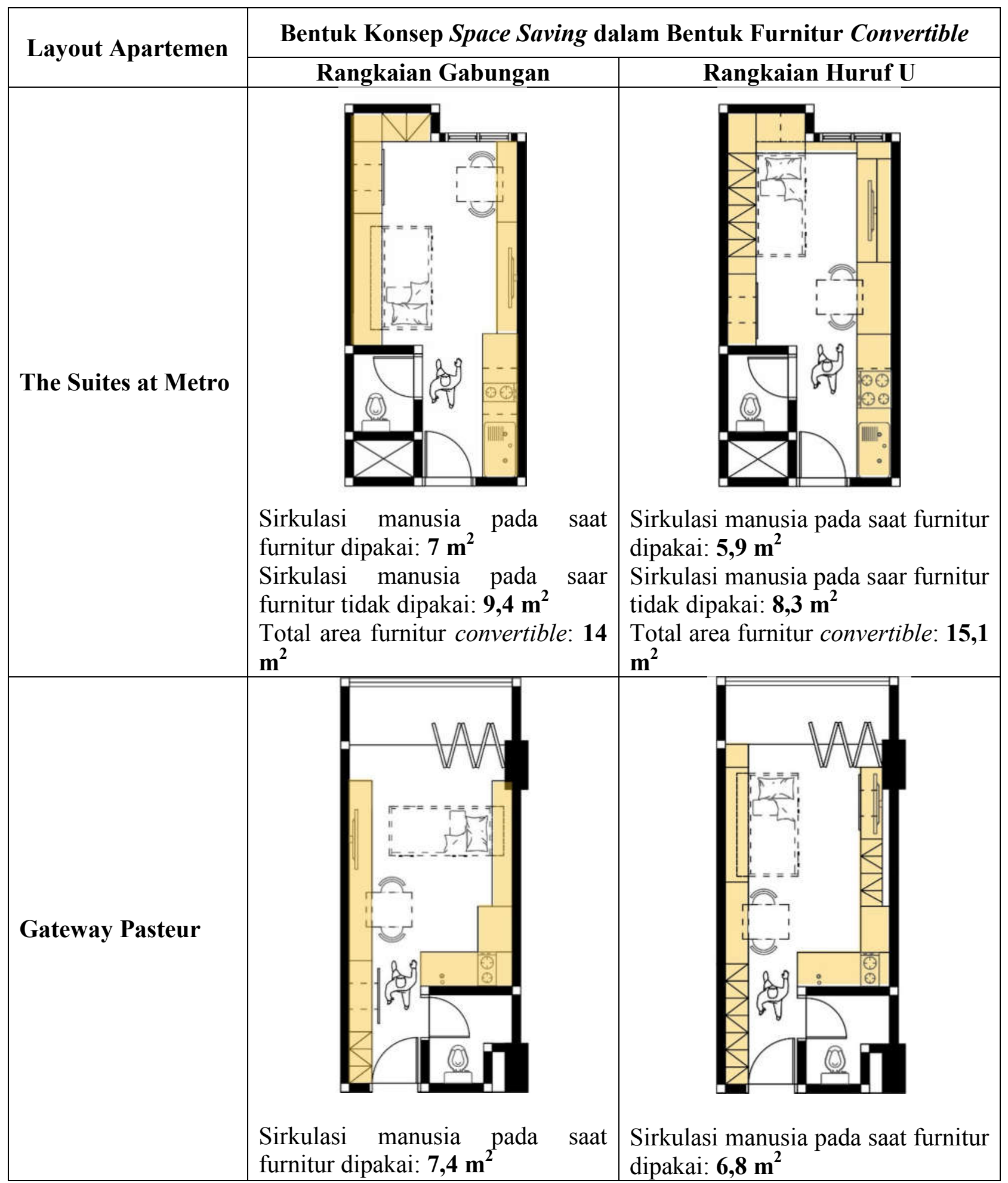




\begin{tabular}{|c|c|c|}
\hline & 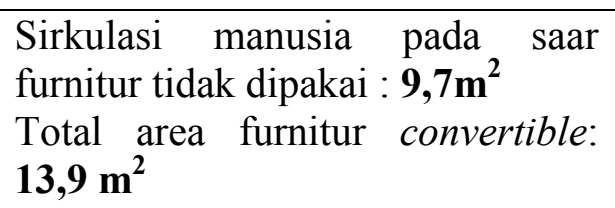 & $\begin{array}{l}\text { Sirkulasi manusia pada saar furnitur } \\
\text { tidak dipakai: } \mathbf{9 , 1} \mathbf{~ m}^{\mathbf{2}} \\
\text { Total area furnitur convertible: } \mathbf{1 4 , 5} \\
\mathbf{m}^{\mathbf{2}}\end{array}$ \\
\hline Sudirman Suite & $\begin{array}{l}\text { Sirkulasi manusia pada saat } \\
\text { furnitur dipakai: } \mathbf{5 , 7} \mathbf{~ m}^{\mathbf{2}} \\
\text { Sirkulasi manusia pada saar } \\
\text { furnitur tidak dipakai: } \mathbf{8 , \mathbf { 1 }} \mathbf{~ m}^{\mathbf{2}} \\
\text { Total area furnitur convertible: } \\
\mathbf{1 3 , 6} \mathbf{~ m}^{\mathbf{2}}\end{array}$ & $\begin{array}{l}\text { Sirkulasi manusia pada saat furnitur } \\
\text { dipakai: } \mathbf{5 , 5} \mathbf{~ m}^{\mathbf{2}} \\
\text { Sirkulasi manusia pada saar furnitur } \\
\text { tidak dipakai: } \mathbf{7 , 8} \mathbf{~ m}^{\mathbf{2}} \\
\text { Total area furnitur convertible: } \mathbf{1 3 , 8} \\
\mathbf{m}^{\mathbf{2}}\end{array}$ \\
\hline
\end{tabular}

Dapat dilihat dari Tabel 3 bahwa furnitur convertible (arsir warna kuning transparan) dapat digunakan pada area tempat tidur serta meja makan. Penggunaan furnitur convertible pada area tempat tidur dan meja makan menggunakan sistem lipat. Sistem lipat pada furnitur digunakan untuk memberikan kenyamanan dalam hal sirkulasi bagi penghuni serta untuk memberikan kegunaan atau fungsi lebih pada tiap furnitur yang tersedia. Sehingga dalam satu ruang apartemen furnitur penunjang kegiatan penghuni tersimpan dalam satu rangkaian dimensi. Lebar dimensi yang digunakan pada tiap ketiga sampel layout apartemen adalah $60 \mathrm{~cm}$. Ukuran dimensi $60 \mathrm{~cm}$ digunakan karena ukuran lebar tersebut dapat menampung berbagai jenis benda serta kebutuhan penghuni mulai dari benda yang berukuran besar seperti kasur, meja makan, serta lemari penyimpanan (baik kabinet pada pantry maupun lemari untuk menyimpan pakaian). 


\section{Hasil/ Temuan}

Berdasarkan pengujian dua tipe rangkaian furnitur convertible pada sample layout yang ada, dapat disimpulkan hasilnya pada tabel dibawah ini:

Tabel 4. Hasil Implementasi Rangkaian Furnitur Convertible terhadap Layout (sumber: Analisis Pribadi)

\begin{tabular}{|c|c|c|}
\hline Layout Apartemen & $\begin{array}{c}\text { Rangkaian Furnitur } \\
\text { Gabungan }\end{array}$ & Rangkaian Huruf U \\
\hline The Suites at Metro & $\sqrt{ }$ & $\sqrt{ }$ \\
\hline Gateway Pasteur & $\sqrt{ }$ & $\mathrm{x}$ \\
\hline Sudirman Suite & $\sqrt{ }$ & $\mathrm{x}$ \\
\hline
\end{tabular}

Tabel 4 menunjukkan bahwa tidak semua layout apartemen dapat diaplikasikan furnitur convertible dengan satu rangkaian yang sama hanya karena bentuk layout ketiga apartemen terlihat sama. Dapat dilihat bahwa rangkaian furnitur convertible gabungan dapat digunakan pada berbagai sample layout apartemen karena posisinya yang menempel pada dinding apartemen dan tidak berbentuk satu kesatuan furnitur seperti rangkaian huruf U. Juga ruang yang terbentuk dari sisa dimensi furnitur yang tak terpakai masih jauh lebih baik dibandingkan dimensi sisa pada layout sebelumnya, membuat penghuni dapat mengakses ruangan dengan lebih leluasa. Sementara untuk rangkaian huruf U, rangkaian furnitur convertible hanya dapat teraplikasi pada layout apartemen The Suite at Metro. Rangkaian furnitur huruf U dapat teraplikasi dengan baik pada layout apartemen The Suite at Metro karena rangkaian tersebut hanya memiliki satu pintu akses utama dan tidak memiliki balkon. Sehingga ruang apartemen The Suite at Metro dapat dikelilingi dengan rangkaian furnitur convertible. Ditambah lagi ruang yang tersisa dari penggunaan furnitur masih dapat digunakan sebagai tempat penyimpanan/ rak, membuat ruangan benar-benar memanfaatkan dimensi furnitur dan ruang dengan baik. Meski dalam kenyataannya, tidak semua layout apartemen tipe studio dapat menerapkan rangkaian furnitur convertible berbentuk $\mathrm{U}$.

Konsep space saving sebenarnya dapat digunakan pada semua sampel layout apartemen. Hanya saja kembali lagi kepada bentukan rangkaian furnitur convertible yang digunakan pada masing-masing layout. Penerapan konsep space saving secara general untuk apartemen tipe studio yang ada di Indonesia dapat dikatakan cukup berhasil karena dapat diaplikasikan pada beberapa layout berbeda, namun kembali lagi pada bentukan furnitur convertible yang akan digunakan. 


\section{Kesimpulan}

Berdasarkan hasil analisis pada objek studi serta pengembangan desain, dapat ditarik kesimpulan, yaitu:

1. Perlunya pembagian ruang utama serta penggabungan beberapa kegiatan/kebutuhan penghuni pada sebuah furnitur.

2. Dilihat dari ukuran luas ruang yang terbatas, bentuk dan ukuran furnitur (dimensi) yang terdapat di dalam apartemen tipe studio harus mampu menampung beberapa kegiatan/fungsi ke dalam sebuah furnitur tertentu. Selain menjadi lebih efisien, pemanfaatan ruang ini pun dapat menghasilkan jalur sirkulasi yang lebih baik untuk penghuni.

3. Penggunaan konsep space saving yang sudah digunakan pada apartemen-apartemen di negara bagian barat dapat digunakan pada apartemen yang ada di Indonesia melalui penggunaan furnitur convertible.

4. Furnitur yang tepat digunakan pada apartemen tipe studio adalah furnitur convertible, yaitu furnitur yang dapat berubah bentuk, fungsi maupun karakternya sesuai dengan kebutuhan pengguna pada saat itu.

5. Perlu adanya standar dimensi untuk menyamaratakan dimensti furnitur yang digunakan pada tiap apartemen yang ada di Indonesia, sehingga memiliki kesamaan ukuran. Salah satunya dengan cara menyamakan lebar dimensi furnitur yang digunakan.

6. Selain itu, sisi dinding apartemen dapat dimanfaatkan sebagai tempat penopang beban furnitur yang dipasang pada bagian dinding, seperti rak/ ambalan.

Dari uraian di atas, dapat disimpulkan bahwa konsep space saving yang sudah berkembang sejak 1915 dapat digunakan pada interior apartemen tipe studio. Konsep space saving yang digunakan tentunya melalui bantuan dimensi serta bentukan furnitur yang akan digunakan. Penggabungan beberapa furnitur menjadi satu sesuai dengan kesamaan kegiatan/fungsi dapat meminimalisasi penggunaan furnitur dalam jumlah yang banyak pada luas apartemen yang terbatas. Sehingga nantinya konsep space saving dengan penggunaan furnitur convertible dapat memberikan kenyamanan bagi penghuni apartemen dan dapat menjadi daya tarik tersendiri bagi pengelola apartemen. 


\section{Daftar Pustaka}

[1] Admin. Space Saving Modular Studio For an Artist Raanan Stern. Tersedia di . Diakses: http://www.dezeen.com/2014/02/25/space-saving-modular-studio-for-anartist-raanan-stern/ 2016-09-07.

[2] Akmal, Imelda. (2007). Menata Apartemen, Gramedia Pustaka Utama, Jakarta.

[3] Anthony D. King. (1984), Buildings and Society: Essay On The Social Development of The Environment, Routledge \& Kegan Paul, London, Halaman. 1.

[4] Cristri, PricilliaEka., \&Kusumarini, Yusita. Perancangan Interior Modular pada Residential Space Tipe Studio, Jurnal Intra, Vol. 2 (2014) No. 2.

[5] Putra, GiwanHardwika. (2014), Efektivitas Ruang Dalam Rumah Tipe 36 Ditinjau Dari Perletakan Perabot Terhadap Ruang Gerak Penghuni, EJournal Graduate Unpar, Vol. 1 No.2. 